\title{
1987: Looking Ahead
}

\section{Kathleen C. Taylor MRS President}

This first 1987 issue of the MRS BULLETIN brings you news of technical meetings and activities planned for 1987. The new year also brings a new cadre of MRS volunteers who will oversee Society activities during the coming year. I wish to introduce these people to you and invite you to let them know your thoughts and suggestions.

The central mission of the Materials Research Society is to serve as the primary interdisciplinary forum for professionals involved in materials research and development. MRS has grown rapidly in recent years. This growth reflects the success of our programs and has come about as a result of the ongoing contributions of all who have worked together to bring these programs to you. The MRS committees are a part of the vital infrastructure through which top researchers contribute to the goals of the Society. Their active involvement in the planning and execution of MRS programs has kept MRS at the cutting edge of the materials field.

The MRS meetings are the focal point of the Society's programs. The Materials Research Society has an established record of dynamic meetings which foster the communication and exchange of technical information. The planning, organization, and execution of the meeting program are the major project of the Program Committee. In the year ahead the MRS Program Committee chaired by Rod Quinn (Los Alamos National Laboratory) will finalize the programs and plans for the 1987 MRS Spring and Fall Meetings and the 1988 MRS Spring Meeting. The Meeting Chairs for the 1987 Spring Meeting are Greg Olson (Hughes Research Laboratories), Graham Hubler (Näval Research Laboratory), and Russ Chianelli (Exxon Research \& Engineering Co.). The Meeting Chairs for Fall 1987 are Tom Picraux (Sandia National Laboratories), Barry Scheetz (Pennsylvania State University), and Murray Gibson (AT\&T Bell Laboratories). The Meeting Chairs for Spring 1988 are Clif Draper (AT\&T Technologies), Dave Clark (University of Florida), and C.T. Liu (Oak Ridge National Laboratory). Plans for the 1988 Fall Meeting are just getting launched. Here the Meeting Chairs will be Slade Cargill (IBM T.J. Watson Research Center), Wayne Goodman (Sandia National Laboratories), and Francis Young (University of Illinois). The Meeting Chairs have broad responsibility for identifying symposia topics, recruiting quali-

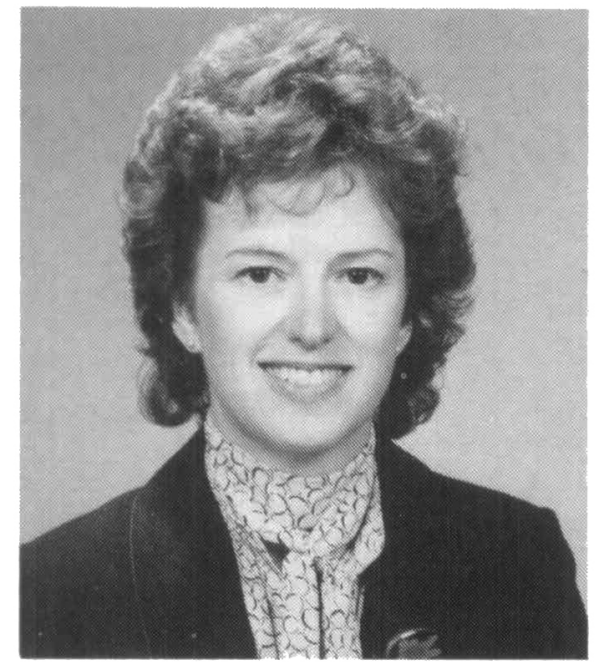

fied people to organize and run symposia, communicating with symposia chairs, and the execution of the meeting on-site. The simultaneous planning of future meetings requires careful coordination among the meeting chairs. Jim Roberto (Oak Ridge National Laboratory), vice-chair of the Program Committee, will chair a new subcommittee which will coordinate technical programming and help identify the new and emerging research areas which should be addressed in MRS meetings.

The MRS Publications Committee chaired by Dave Campbell (IBM East Fishkill Facility) oversees the production of all MRS publications, including the MRS Proceedings series, Journal of Materials Research, the MRS BULLETIN, and the new MRS Conference Proceedings series. In 1987 Walter Brown (AT\&T Bell Laboratories) will come on board as Editorin-Chief of Journal of Materials Research and, as such, is an ex-officio member of the Publications Committee. Journal of Materials Research was very successfully launched in 1986 under the competent direction of its first Editor-in-Chief, Charles B. Duke (Xerox Webster Research Center). Support for the growth of $J M R$ in the coming year will be a major activity for the Publications Committee. Jeff Gambino (IBM Fishkill Facilities) will oversee this project. The MRS Proceedings series, which publishes papers presented at MRS meetings, has a proven reputation of bringing the content of MRS meetings to a wide audience in a timely way at affordable prices. The Proceedings Subcommittee, chaired by Peter Pronko (Universal Energy Systems), reviews all proposals for publication of proceedings volumes. In

\section{The MRS committees are a part of the vital infrastructure through which top researchers contribute to the goals of the Society.}

1987 Elton Kaufmann (Lawrence Livermore National Laboratory) will continue as chairman of the BULLETIN Editorial Board. The MRS BULLETIN is the Society's organ to provide information of general interest to the materials research community. Plans for the BULLETIN for 1987 include increasing the number of issues from six to eight.

In 1987 the two cochairs of the Education Committee will be Al Romig (Sandia National Laboratories) for continuing education in materials research and Gary Tibbetts (General Motors Research Laboratories) for university issues. Al Romig and his part of the Education Committee will initiate the development of new MRS short courses. The Society's short course program has been expanded to include a full program of courses - at both the Spring and Fall Meetings - aimed to complement the topical content of MRS symposia. In addition, a new program of On-Site short courses was launched in 1986. Currently 34 courses are available to industrial or other sponsoring groups. In 1987 Gary Tibbetts will be the contact for MRS Student Chapters, keeping the chapters up to date on MRS activities and helping the chapters with meeting plans. The recent formation of a new MRS Student Chapter at the University of WisconsinMadison brings the number of MRS Student Chapters to ten.

The External Affairs Committee of the Materials Research Society will continue to oversee our relations with other scientific and technical societies, will carry on discussions with groups interested in forming "MRS-type" organizations, will be the

Continued 
contact point in MRS for communication with E-MRS, and will consider new projects on issues of concern to the materials research community. In 1987 Elton Kaufmann (Lawrence Livermore Laboratory) will chair the External Affairs Committee. Bob Chang (Northwestern University) will continue as chair of the Subcommittee on International Relations, and Gordon Pike (Sandia National Laboratories) will chair the Subcommittee on Intersociety Relations.

The Public Relations and Publicity Committee is chaired this year by Carol Jantzen (E.I. du Pont de Nemours-Savannah River Lab) and is responsible for publicizing the activities of the Materials Research Society both to members through the MRS BULLETIN and to nonmembers through articles and calendar entries in appropriate publications. The Finance Committee chaired by Clif Draper (AT\&T Technologies) is responsible for the financial health of MRS. This committee examines the detailed budgets of the Society and makes recommendations on fund raising activities. The Corporate Participation Committee is chaired this year by Mike Quick (Engelhard Corporation) and is responsible for involving corporations in the support of symposia at MRS meetings and in the general support of society activities such as the Awards Program. The Membership Committee under Julia Phillips (AT\&T Bell Laboratories) has the task of adding to the membership base of the Society, fostering and monitoring the creation of MRS Sections, and reviewing appropriate benefit plans for members of the Society. MRS headquarters, founded three years ago, provides essential support for all Society activities. MRS headquarters has now very competently taken over most of the nontechnical work of operating the Society and is an important resource to the committees and the elected officers.

I have tried to tell you what our volunteers will be doing in the year ahead and why their contributions are essential to MRS. In the past few years MRS has initiated many activities which will require the continued attention of individuals volunteering their time and talent in order to achieve our objectives.

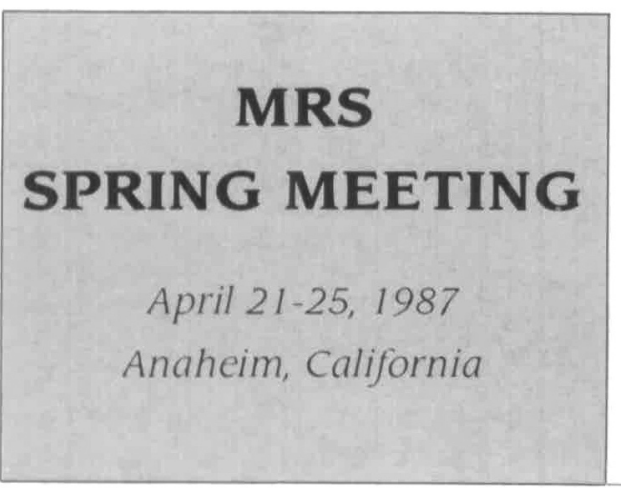

\section{The New Watch-Word in Cryogenic Temperature Sensors:}

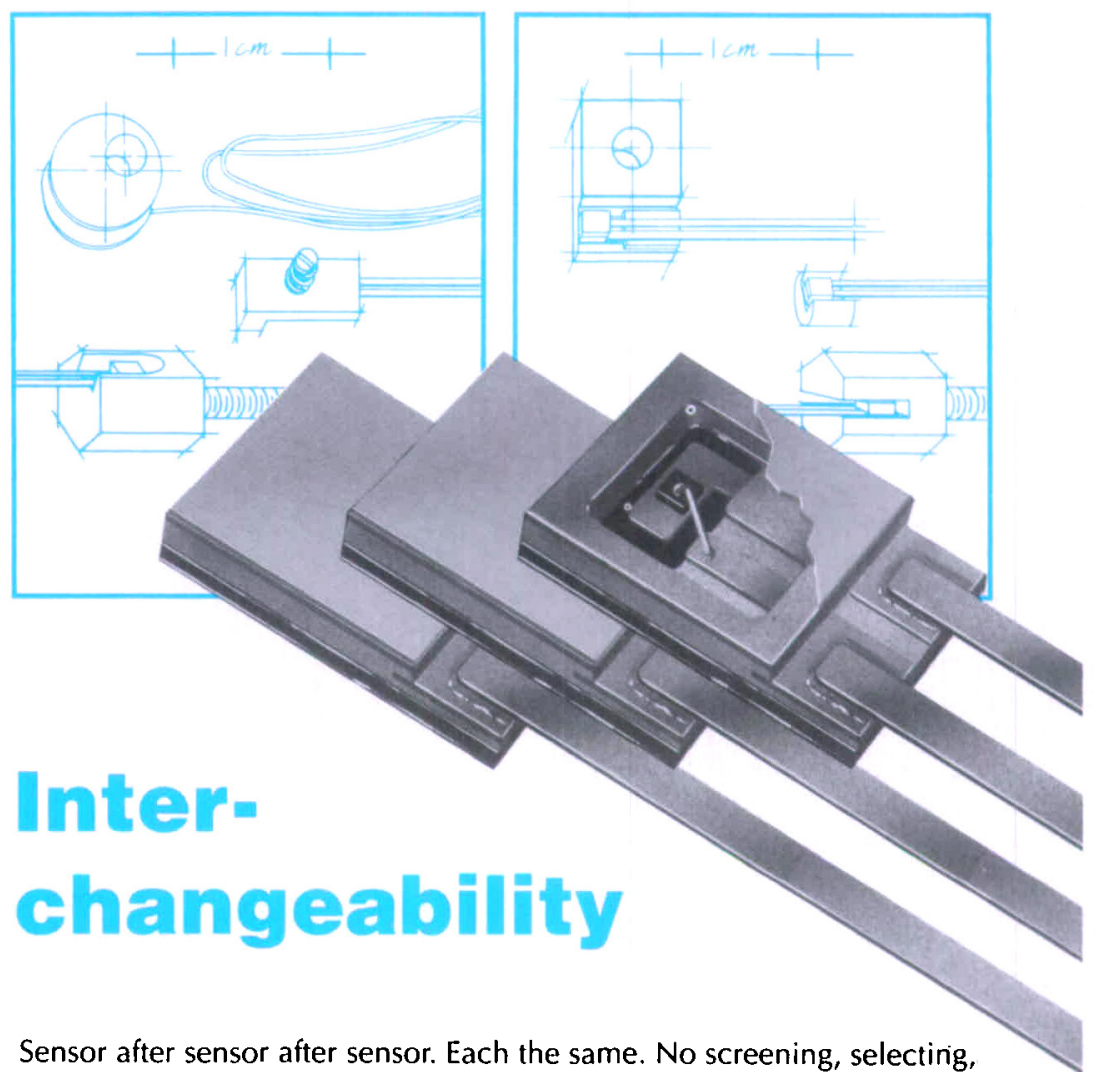
calibrating ...no hassle. It's a new phenomenon in cryogenic thermometry and it separates Lake Shore DT-470 Diode Temperature Sensors from all the others.

Now you can order as many accurate, stable, repeatable, fast, wide range, INTERCHANGEABLE, Model DT-470 Sensors as you need. Prices are low, delivery off-the-shelf.

Lake Shore's new INTERCHANGEABLE Sensors are founded in two key component developments:

- Virtually ideal temperature sensing elements that exhibit precise, repeatable, monotonic thermal response over a wide temperature range.

- Custom, hermetically-sealed, sapphire-based ceramic sensor packages that preserve all the thermal attributes of the sensing element.

Meticulous assembly of the sensors on state-of-the-art bonding equipment in a semiconductor-grade clean room keeps them free of epoxies, polyimides, fluxes and other contaminants. Verification of every sensor over its entire temperature range assures the reliability you expect from us.

Whatever your cryogenic temperature needs: generation, detection, measurement, control, and more to be announced soon, give us a call. At Lake Shore ... we know cryogenics COLD! 